ISSN: 1829-6750 Inovasi Kurikulum, Februari 2008, Thn. 5. Vol 5 Nomor: 1

\title{
EVALUASI IMPLEMENTASI KTSP PADA ASPEK KOMPETENSI PENGELOLAAN PEMBELAJARAN DI SMK
}

\section{Sunarto Halim Untung}

\begin{abstract}
Abstrak. Kurikulum senantiasa direvisi untuk mewujudkan kurikulum yang sesuai dengan tuntutan dan kebutuhan masyarakat, guna mengantisipasi perkembangan jaman, serta memberikan guideline atau acuan bagi penyelenggaraan pembelajaran di satuan pendidikan. Kurikulum Tingkat Satuan Pendidikan (KTSP) dikembangkan sesuai dengan satuan pendidikan, potensi daerah/karakteristik daerah, sosial budaya masyarakat setempat, dan peserta didik. KTSP akan membuat guru semakin kreatif, karena mereka dituntut harus merencanakan sendiri materi pelajarannya untuk mencapai kompetensi yang telah ditetapkan. Pada pelaksanaannya masih timbul hambatan pelaksanaan KTSP di sekolah pada unsur guru. Implementasi KTSP masih diwarnai minimnya sosialisasi dan persiapan guru. Timbul pertanyaan bagaimana mungkin KTSP berhasil diterapkan di sekolah jika para guru masih belum memahami konsep, substansi, dan mekanisme pelaksanaan KTSP. Jika masalah ini dibiarkan maka akan sia-sia apa yang telah dilakukan oleh pemerintah dan penentu kebijakan pendidikan, sehingga dalam konteks ini perlu dipahami bahwa pentingnya sebuah kesiapan yang harus dimiliki guru.

Permasalahan di atas, diteliti melalui evaluasi implementasi KTSP pada aspek Kompetensi pengelolaan pembelajaran menggunakan model perbandingan antara standar evaluasi dengan hasil observasi (standard vs observ). Subjek penelitian adalah guru Mata Diklat Teknik Gambar Mesin di SMKN 2 Bandung. Instrument penelitian berupa: observasi, wawancara dan studi dokumentasi yang perangkatnya di jadment oleh ahlinya.
\end{abstract}


ISSN: 1829-6750 Inovasi Kurikulum, Februari 2008, Thn. 5. Vol 5 Nomor: 1

Hasil penelitian menunjukkan bahwa Rencana pelaksanaan pembelajaran (RPP) yang dibuat kelompok guru dibandingkan dengan rambu-rambu petunjuk penyusunan RPP yang terdapat pada dokumen KTSP, diperoleh ketercapaian 33\% dibandigkan standar aspek perencanaan pembelajaran menurut KTSP di SMK. Pelaksanaan pembelajaran diperoleh ketercapaian 52,371\%. Sedangkan Pengelolaan pembelajaran secara utuh diperoleh ketercapaian 60,17.5\%.

Kata kunci: KTSP

\section{A. Pendahuluan}

Kurikulum merupakan salah satu komponen yang sangat penting dalam penyelenggaraan Pendidikan. Kurikulum digunakan sebagai acuan penyelenggaraan pendidikan dan sekaligus sebagai salah satu indikator mutu pendidikan. Di Indonesia tercatat telah lima kali revisi kurikulum pendidikan dasar dan menengah. Revisi kurikulum tersebut bertujuan untuk mewujudkan kurikulum yang sesuai dengan tuntutan dan jaman, serta memberikan guideline atau acuan bagi penyelenggaraan

pembelajaran di satuan pendidikan.

Kurikulum terbaru yang dikembangkan adalah Kurikulum Tingkat Satuan Pendidikan (KTSP) sesuai dengan satuan pendidikan, potensi daerah/karakteristik daerah, sosial budaya masyarakat setempat, dan peserta didik. Kurikulum tingkat satuan pendidikan akan membuat guru semakin kreatif, karena mereka 
ISSN: 1829-6750 Inovasi Kurikulum, Februari 2008, Thn. 5. Vol 5 Nomor: 1

dituntut harus merencanakan sendiri materi pelajarannya untuk mencapai kompetensi yang telah ditetapkan. Kurikulum yang selama ini dibuat dari pusat, menyebabkan kreatifitas guru kurang terpupuk tetapi dengan KTSP kreatifitas berkembang. Hanya saja sebagian besar guru tidak terbiasa

mengembangkan modelmodel kurikulum. Selama ini mereka diperintah untuk melaksanakan kewajiban yang sudah baku, yaitu kurikulum yang dibuat dari pusat

Mutaqin,2006).

Hambatan pelaksanaan KTSP di sekolah terletak pada tiga komponen yaitu unsur guru, unsur pengelolaan sekolah (kepala sekolah, komite sekolah, dan pelanggan pendidikan), dan birokrasi pendidikan. Untuk unsur guru, diperlukan beberapa kompetensi guru untuk memahami keterlaksanaan KTSP, yang utama adalah
Kompetensi

pengelolaan

pembelajaran.

(D.Zainal

Mutaqin,2006).

Guru merupakan faktor penting yang besar pengaruhnya terhadap proses dan hasil belajar, bahkan sangat menentukan berhasiltidaknya peserta didik dalam belajar. Demikian halnya dengan pengembangan KTSP yang menuntut kreatifitas guru dalam membentuk kompetensi pribadi peserta didik. Guru perlu memperhatikan perbedaan individual peserta didik, agar KTSP dapat dikembangkan secara efektif, serta dapat meningkatkan kualitas pembelajaran (Mulyasa, 2007:164)

Implementasi KTSP masih diwarnai minimnya sosialisasi dan persiapan guru. Sementara itu, fakta di lapangan yang penulis peroleh sebagai gambaran awal dari penelitian ini adalah para guru memiliki pemahaman yang berbedabeda tentang KTSP. Hal ini 
ISSN: 1829-6750 Inovasi Kurikulum, Februari 2008, Thn. 5. Vol 5 Nomor: 1

dikarenakan untuk diklat dan pelatihan hanya guru-guru tertentu yang mengikutinya, tentu saja hal tersebut menyebabkan hanya sebagian guru saja yang memahami KTSP tersebut, selain itu banyak sekali guru-guru senior yang menganggap bahwa KTSP tersebut tidak ada bedanya dengan sistem pengajaran yang terdahulu, mereka terbiasa dengan pola pengajaran yang umum dilakukan (menggunakan metoda ceramah dalam pencapaian informasi) dan mereka enggan mengganti pola pengajaran tersebut, dikarenakan pola yang terdahulu dianggap telah berhasil. Dari fenomena itulah, kemudian berkembang plesetan dikalangan guru; "Kurikulum Terserah Sekolah Panjenengan". Misalnya, mereka bertanya bagaimana mungkin KTSP berhasil diterapkan di sekolah jika para guru masih juga mengalami kebingungan dalam menangkap konsep, substansi, dan mekanisme pelaksanaan KTSP. Dalam konteks ini perlu dipahami bahwa pentingnya sebuah kesiapan yang harus dimiliki guru.

Berdasarkan penelaahan permasalahan di atas, maka studi penelitian ini berupaya mendeskripsikan evaluasi implementasi KTSP di Sekolah Menengah Kejuruan Negeri 2 Bandung karena sebagai basis nasional dalam implementasi KTSP. Penelaahan hanya dilakukan pada masalah yang berkaitan dengan unsur guru, dan dibatasi pula pada Kesiapan guru dalam pengelolaan pembelajaran yang terdiri dari: menyusun rencana pemelajaran, pelaksanaan pemelajaran, evaluasi pemelajaran dan melaksanakan tindak lanjut hasil pembelajaran

Pertanyaan penelitian dalam hal ini adalah Bagaimana implementasi KTSP pada aspek Kompetensi Pengelolaan Pembelajaran mata diklat teknik gambar 
ISSN: 1829-6750 Inovasi Kurikulum, Februari 2008, Thn. 5. Vol 5 Nomor: 1

mesin DI SMK. Apakah sesuai dengan kompetensi pengelolaan pembelajaran yang ditetapkan dalam rambu-rambu KTSP?

\section{B. Landasan Teori}

Kesiapan sangat penting untuk memulai suatu pekerjaan, karena dengan memiliki kesiapan pekerjaan, apapun akan dapat teratasi dan dikerjakan dengan lancar dan hasil yang baik.

Beberapa prinsip kesiapan menurut Slameto (1995:117), adalah sebagai berikut:

a. Semua perkembangan berinteraksi mempengaruhi)

b. Kematangan jasmani dan rohani adalah perlu untuk memperoleh manfaat dan pengalaman.

c. Pengalaman-pengalaman mempunyai yang positif terhadap kesiapan.

d. Kesiapan dasar untuk kegiatan tertentu terbentuk dalam periode tertentu selama masa pembentukan dan masa perkembangan

Kesiapan guru dalam proses pembelajaran yang dilakukan sangat relevan dengan teori kematangan dan produktivitas pekerjaan dalam suatu organisasi. Heresy dan Banchard (Nono Caryono, 2005:17) mengemukakan konsep kematangan pekerja sebagai “ kemampuan dan kemauan (ability and willingness) orang-orang untuk memikul tanggung jawab untuk mengarahkan prilaku mereka sendiri". Dalam hal ini, Hersey dan Blanchard mengatakan bahwa variabel variabel kematangan itu hendaknya dipertimbangkan dalam kaitanya dengan tugas tertentu yang perlu dilakukan. Berkaitan dengan kesiapan guru, maka seorang guru 
ISSN: 1829-6750 Inovasi Kurikulum, Februari 2008, Thn. 5. Vol 5 Nomor: 1

harus mengetahui tugas dan profil guru, peranan guru, kinerja guru, profesionallisme guru, standar pengembangan guru. Hal ini dimaksud agar setiap guru sebelum kelapangan melalui proses pembelajaran, dapat memiliki kesiapan pada kegiatan pembelajaran.

Sebagaimana diketahui bahwa proses pembelajaran dan hasil belajar siswa sebagian besar ditentukan oleh peran dan kompetensi seorang

Konsekuensinya guru. guru harus

menyiapkan seorang mampu meningkatkan peran dan kompetensinya. Guru yang berkopeten akan lebih mampu mengelola kelasnya sehingga hasil belajar siswa berada pada tingkat optimal. Peran dan kompetensi guru dalam proses pemelajaran meliputi banyak hal. Antara lain guru demonstrator, kelas, mediator sebagai fasilitator, dan evaluator.
Kinerja dalam Kamus Besar Bahasa Indonesia berarti suatu yang dicapai, prestasi yang diperlihatkan atau kemampuan kerja (Balai Pustaka, 1985:503). Sedangkan menurut bernandi dan Russel dalam Febiyani (2003:22) menyatakan bahwa:

Kinerja adalah hasil dari fungsi suatu pekerjaan atau kegiatan tertentu selama priode tertentu atau perwujutan dari hasil perpaduan yang sinergis dan akan terlihat dari produktivitas seseorang dalam melaksanakan tugas dan pekerjaannya.

Kurikulum Tingkat Satuan Pendidikan (KTSP) adalah sebuah kurikulum operasional pendidikan yang disusun oleh dan dilaksanakan di masingmasing satuan pendidikan. KTSP diberlakukan di Indonesia mulai tahun ajaran 2006/2007, menggantikan kurikulum 2004 (Kurikulum Berbasis Kompetensi). KTSP 
ISSN: 1829-6750 Inovasi Kurikulum, Februari 2008, Thn. 5. Vol 5 Nomor: 1

terdiri dari tujuan pendidikan tingkat satuan pendidikan, struktur dan muatan kurikulum tingkat satuan pendidikan, kalender pendidikan, dan silabus. KTSP diamanatkan oleh Undang-undang nomor 20 Tahun 2003 tentang Sistem Pendidikan Nsional dan Peraturan Pemerintah Republik Indonesia Nomor 19 Tahun 2005 tentang Standar Nasional Pendidikan. KTSP berlaku pada jenjang pendidikan dasar (Sekolah Dasar dan Sekolah Menengah Pertama) dan menengah (Sekolah Menengah Atas dan Sekolah Menengah Kejuruan), dan disusun oleh satuan pendidikan dengan mengacu kepada Standar Isi (SI) dan Standar Kompetensi Lulusan (SKL) serta berpedoman pada panduan yang disusun oleh Badan Standar Nasional Pendidikan (BSNP). Standar isi adalah ruang lingkup materi dan tingkat kompetensi yang dituangkan dalam persyaratan kompetensi kompetensi bahan kajian kompetensi mata pelajaran, dan silabus pembelajaran yang harus dipenuhi peserta didik pada jenjang dan jenis pendidikan tertentu.

Kurikulum tingkat satuan pendidikan di sekolah dikembangkan dengan berpedoman pada standar kompetensi lulusan dan standar isi serta paduan penyusunan kurikulum yang dibuat oleh BSNP, Zainal Mutaqin (2007). Dalam komponen KTSP meliputi :

1. Tujuan

Pendidikan Sekolah

2. Struktur dan Muatan Kurikulum (mata pelajaran. Muatan lokal, pengembangan diri, beban belajar, ketuntasan belajar, kenaikan kelas dan kelulusan, penjurusan, pendidikan kecakapan hidup, pendidikan berbasis keunggulan lokal dan global). 
ISSN: 1829-6750 Inovasi Kurikulum, Februari 2008, Thn. 5. Vol 5 Nomor: 1

3. Kalender pendidikan

4. Silabus dan RPP

(Sosialisasi dan Implementasi KTSP. Jakarta:Depdiknas, Januari 2007)

\section{Metode Penelitian}

Metode yang digunakan dalam penelitian ini adalah metode

implementasi

dimaksudkan

mengetahui kesiapan guru dalam meimpelemtasikan KTSP di SMKN 2 Bandung. Subjek penelitian adalah Guru diklat pada mata diklat Teknik Gambar Mesin di SMKN 2 Bandung. Teknik Pengumpulan data yang dilakukan, yaitu: Studi lapangan (observasi), wawancara, dan studi dokumentasi.

Proses analisis data dimulai dengan menelaah seluruh data yang tersedia dari berbagai sumber, yaitu dari wawancara, observasi yang sudah dituliskan dalam catatan lapangan, dokumen pribadi, dokumen resmi, dan sebagainya. Analisis data yang digunakan pada penelitian ini terdiri dari 1). Reduksi data; 2). Penyajian data; 3). Mengambil kesimpulan dan verifikasi.

Generalisasi diambil setelah fakta yang merupakan fokus permasalahan penelitian, teramati di lapangan. Dalam penelitian ini, fakta-fakta yang terjadi di lapangan tentang implementasi/ pelaksanaan KTSP dibandingkan dengan standar implementasi/pelaksanaan

KTSP.

\section{Hasil Penelitian}

Kompetensi pengelolaan pembelajaran aspek yang diteliti adalah: menyusun rencana pelaksanaan pembelajaran (RPP), dan melaksanakan proses pembelajaran. Pengumpulan data dilakukan dalam bentuk 
ISSN: 1829-6750 Inovasi Kurikulum, Februari 2008, Thn. 5. Vol 5 Nomor: 1

analisis dokumen RPP, Hasil penelitian diperoleh wawancara, dan observasi Rencana pelaksanaan langsung dengan responden. pembelajaran (RPP) yang Analisis dokumen RPP dibuat secara berkelompok digunakan untuk melengkapi dibandingkan dengan rambudata yang diperoleh dari hasil rambu petunjuk penyusunan wawancara dan observasi. RPP terdapat pada dokumen Komponen RPP terdiri dari KTSP. Persentase pembuatan tujuan pembelajaran, materi RPP berdasarkan observasi pembelajaran, metoda pembelajaran, sumber belajar, dan penilaian hasil belajar. Kompetensi pengelolaan pembelajaran aspek awal yang diamati adalah susunan rencana pembelajaran (RPP), secara umum responden dalam menyusun RPP dilakukan secara tim. RPP yang dibuat kelompok guru dibandingkan dengan rambu-rambu petunjuk penyusunan RPP yang terdapat pada dokumen KTSP atau dibandigkan standar aspek perencanaan pembelajaran menurut KTSP di SMK. Begitu pula untuk Pelaksanaan Pembelajaran, dan akhirnya untuk keseluruhan Pengelolaan Pembelajaran. untuk responden adalah $33.3 \%$. Responden dalam merumuskan tujuan pembelajaran hanya menggambarkan aspek psikomotor, tidak ada penjabaran kriteria kinerja, materi pembelajaran disusun bertahap berdasarkan tingkat kesukaran rendah ke tinggi tidak dirancang proporsional, tidak ada langkah-langkah pembelajaran (skenario), tidak dicantumkan penggunaan jenis media, dan tahap-tahap proses evaluasi tidak dijelaskan secara rinci dalam dokumen RPP. Hasil observasi susunan RPP, tim guru diklat gambar teknik belum sesuai dengan petunjuk dokumen KTSP. 
ISSN: 1829-6750 Inovasi Kurikulum, Februari 2008, Thn. 5. Vol 5 Nomor: 1

Pelaksanaan pembelajaran, pengumpulan data dilakukan dalam bentuk observasi langsung dengan responden, diketahui bahwa dalam pelaksanaan pembelajaran guru diklat gambar teknik melaksanakan tanpa skenario RPP. Prosentase Pelaksanaan pembelajaran yang dibuat responden diperoleh hasil $52,371 \%$. Umumnya tidak membuat kaitan materi ajar sebelumnya dengan materi yang akan diajarkan. Proses pembelajaran yang dilakukan oleh responden adalah metoda ceramah, peran serta peserta diklat masih kurang, mobilitas posisi responden kurang di dalam kelas, hanya sedikit siswa yang bertanya dan merespon proses pembelajaran kepada guru diklat. Responden lebih banyak berada di depan peserta didik. Persentase pelaksanaan pembelajaran tanpa skenario RPP untuk responden di lapangan dapat digambarkan pada diagram berikut:
Berdasarkan

observasi susunan RPP dan observasi pelaksanaan pembelajaran, disimpulkan kompetensi pengelolaan pembelajaran memiliki nilai persentase $60,17.5 \%$.

\section{E. Simpulan}

Hasil penelitian menunjukkan bahwa Rencana pelaksanaan pembelajaran (RPP) yang dibuat kelompok guru dibandingkan dengan ramburambu petunjuk penyusunan RPP yang terdapat pada dokumen KTSP, diperoleh ketercapaian $33 \%$ dibandigkan standar aspek perencanaan pembelajaran menurut KTSP di SMK. Pelaksanaan pembelajaran diperoleh ketercapaian 52,371\%. Sedangkan Pengelolaan pembelajaran secara utuh diperoleh ketercapaian 60,17.5\%. 
ISSN: 1829-6750 Inovasi Kurikulum, Februari 2008, Thn. 5. Vol 5 Nomor: 1

Daftar Pustaka

Arikunto, S.(1999) Dasar dasar Evaluasi

Pendidikan. Jakarta:

Bumi Aksara

Depdiknas. (2007). Materi sosialisasi dan Pelatian Kurikulum Tingkat satuan Pendidikan (KTSP).Jakarta:

Depdiknas.

. (2007). Standar Kompetensi Guru. Jakarta: Depdiknas

Febiyani.

(2003).

Pengembangan Kualitas Kinerja Guru. Tesis Master pada FIP UPI Bandung: Tidak diterbitkan

Hamalik,

O.

(1995).

Kurikulum dan

Pembelajaran. Jakarta:

Bumi Aksara.

Moleong, Lexy. J. (2004).

Metodologi Penelitian
Kualitatif. Bandung:

Remaja Rosdakarya

Mulyasa, E.(2007) Kurikulum Tingkat

Satuan

Pendidikan. Bandung:

Rosdakarya

Nasution, S.(1982).Asas-asas

Kurikulum. Bandung: Jemmars.

Slameto. (1995). Belajar dan Faktor-faktor yang Mempengaruhinya. Jakarta: Rineka Cipta.

Sudjana, N.

(1989). Penelitian Pendidikan. Bandung: Sinar Baru

Sugiyono. (2007). Metoda Penelitian Kuantitatif Kualitatif dan $R \& D$. Bandung: Alfabeta

Supriadi. (1998). Educational Leadership. Tersedia: hhtp://artikel.us/amhasan .html 
ISSN: 1829-6750 Inovasi Kurikulum, Februari 2008, Thn. 5. Vol 5 Nomor: 1

Syah, M. (2006). Psikologi

Pendidikan. Bandung:

Rosdakarya

Zainal Mutaqin, D.(2006).

Seminar Pelaksanaan

KTSP Di Sekolah.

Bandung: Depdiknas

Kota bandung 